\title{
Early intravenous unfractionated heparin and outcome in acute lung injury and acute respiratory distress syndrome - a retrospective propensity matched cohort study
}

\author{
Jorrit J Hofstra ${ }^{1,2,3^{*}}$, Alexander P J Vlaar ${ }^{1,2,4}$, David J Prins' ${ }^{1}$, Gavin Koh ${ }^{4,5}$, Marcel Levi ${ }^{4}$, Marcus J Schultz ${ }^{1,2}$,
} Jan M Binnekade ${ }^{1}$ and Nicole $P$ Juffermans ${ }^{1,2}$

\begin{abstract}
Background: Acute lung injury (ALI) is characterized by a pro-coagulant state. Heparin is an anticoagulant with anti-inflammatory properties. Unfractionated heparin has been found to be protective in experimental models of ALI. We hypothesized that an intravenous therapeutic dose of unfractionated heparin would favorably influence outcome of critically ill patients diagnosed with ALI.
\end{abstract}

Methods: Patients admitted to the Intensive Care Unit (ICU) of a tertiary referral center in the Netherlands between November 2004 and October 2007 were screened. Patients who developed ALI (consensus definition) were included. In this cohort, the impact of heparin use on mortality was assessed by logistic regression analysis in a propensity matched case-control design.

Results: Of 5,561 admitted patients, 2,138 patients had a length of stay $>48$ hours, of whom 723 were diagnosed with ALI (34\%), of whom 164 received intravenous heparin. In a propensity score adjusted logistic regression analysis, heparin use did not influence 28-day mortality (odds ratio 1.23 [confidence interval 95\% 0.80-1.89], nor did it affect ICU length of stay.

Conclusions: Administration of therapeutic doses of intravenous unfractionated heparin was not associated with reduced mortality in critically ill patients diagnosed with ALI. Heparin treatment did not increase transfusion requirements. These results may help in the design of prospective trials evaluating the use of heparin as adjunctive treatment for ALI.

Keywords: Acute lung injury, Heparin, Case-control study, Critical illness

\section{Background}

Acute lung injury (ALI), and its more severe form Acute Respiratory Distress Syndrome (ARDS), are characterized by an exaggerated pulmonary pro-inflammatory and pro-coagulant response of the host against some form of insult. In sepsis, activation of coagulation as well as

\footnotetext{
*Correspondence: j.j.hofstra@amc.uva.nl

1 Department of Intensive Care Medicine, Academic Medical Center,

University of Amsterdam, Meibergdreef 9, 1105 AZ Amsterdam,

The Netherlands

2Laboratory for Experimental Intensive Care and Anesthesiology (L.E.I.C.A.),

Academic Medical Center, University of Amsterdam, Meibergdreef 9, 1105 AZ

Amsterdam, The Netherlands

Full list of author information is available at the end of the article
}

defective anticoagulant pathways and inhibition of fibrinolysis all contribute to systemic coagulopathy [1]. Similar disturbances in coagulation and fibrinolysis have been found locally in models of ALI [2-4] and in lungs of patients with ALI/ARDS [5,6]. There is evidence that this coagulopathy contributes to pulmonary inflammation $[7,8]$, as the extent of coagulopathy is independently associated with adverse clinical outcomes in patients with ALI/ARDS [8,9]. As such, the pathogenesis of ALI/ ARDS shares many similarities to sepsis $[5,6]$ independent of the occurrence of sepsis [8]. Mechanical ventilation also induces fibrin deposition in the lung, thereby contributing to lung injury [8]. Infusion of recombinant 
human activated protein $\mathrm{C}$ (APC) was found to reduce mortality in patients with severe sepsis in a large phase III clinical trial [10], although this was offset by a recently finished trial of patients with septic shock [11]. A non-randomized subgroup analysis showed that APC was particularly effective in patients who presented with severe community-acquired pneumonia as the source of sepsis, although these findings were not confirmed in a clinical trial of sepsis patients with a low risk of death [12] or the recently finished trial of patients with septic shock [11]. The beneficial effect of APC in patients with severe sepsis observed in the PROWESS trial could, at least partially, be attributed to the effects of APC on lung coagulation [13,14]. A retrospective cohort study suggested that early administration of heparin is of benefit in patients diagnosed with septic shock [15], although this was not confirmed by a prospective clinical trial [16].

Studies evaluating the effect of anticoagulant therapy in ALI, mostly in experimental settings, are promising $[17,18]$. Animal studies have demonstrated that administration of heparins, APC, antithrombin (AT), tissue factor-factor VIIa (TF-FVIIa) pathway inhibitors, plasminogen activators and thrombomodulin can attenuate pulmonary coagulopathy, reduce lung injury and/or improve oxygenation [19].

Besides its anticoagulant effects, unfractionated heparin has been shown to have a wide range of antiinflammatory and immunomodulatory effects [20-22]. Infusion of heparin was found to limit lung injury in endotoxemic swine [23] and mice [24] and reduced pulmonary fibrin depositions in a combined model of smoke inhalation and lung injury in sheep, thereby improving oxygenation [25]. In a rat model of acute lung injury, heparin was found to have positive effects through inhibiting nitric oxide synthase [26]. Further, low molecular weight heparin reduced hyperoxiainduced lung injury in mice through protein kinase interactions [27]. In a clinical study, nebulized heparin was found to significantly reduce activation of coagulation in the lungs of ALI patients [28], further underlining the hypothesis that unfractionated heparin could favorably influence outcome of ALI.

A significant subset of critically ill patients with ALI/ ARDS receives heparin early after admission to the ICU [15]. Indications for heparin include respiratory insufficiency due to myocardial infarction, (suspected) venous thromboembolism, atrial fibrillation and coumarin derivate treatment prior to ICU admission. Another indication for heparin treatment is the use of renal replacement therapy. Given the anticoagulant and anti-inflammatory properties of heparin, we hypothesized that early heparin is associated with reduced mortality among patients diagnosed with ALI/ARDS. Therefore, we evaluated the impact of systemically administered therapeutic dose of heparin on outcome in ALI patients in terms of mortality as well as length of ICU stay.

\section{Methods \\ Design}

This is a nested case control study design, derived from a retrospective cohort of ALI/ARDS patients [29]. The study was approved by the Medical Ethics Committee of the Academic Medical Center, Amsterdam, The Netherlands (reference 08.17.0964), who waived the requirement for individual informed consent in view of the retrospective nature of this research.

\section{Patient population}

Using an electronic patient data monitoring system, all patients with a first admission to the mixed medicalsurgical Intensive Care ward of a tertiary referral center in the Netherlands from 1 November 2004 until 1 October 2007 were reviewed and screened. Patients who developed ALI (consensus definition) were included. In order to determine the effect of heparin on patients who develop ALI while being on the ICU, patients with a length of stay shorter than 48 hours were excluded.

ALI was defined using the consensus definition of ALI: new onset hypoxemia or deterioration, demonstrated by a $\mathrm{PaO}_{2} / \mathrm{FiO}_{2}<300 \mathrm{mmHg}$, with bilateral pulmonary changes, in the absence of cardiogenic pulmonary edema [30]. Pulmonary edema was diagnosed as being of cardiogenic origin if the pulmonary arterial occlusion pressure was $>18 \mathrm{mmHg}$. In the absence of pulmonary artery wedge catheter measurements, cardiac failure was diagnosed if two of the following were present: central venous pressure $>15 \mathrm{mmHg}$, a history of heart failure or valve dysfunction, ejection fraction $<45 \%$ as estimated by echocardiogram, or a positive fluid balance. The probability of cardiogenic pulmonary edema was scored by two physicians independently on a scale of 1-4 (APJV and NPJ) [31]. Chest radiographs were scored for the presence of new onset bilateral interstitial abnormalities by two independent physicians who were blinded to the predictor variables. When interpretation differed, chest radiograph and the description by the radiologist were reviewed and discussed until consensus was reached. Use of heparin was scored when patients received heparin within 48 hours of diagnosis of AL/ARDS.

\section{Patient data collection}

All data was collected from our hospital patient database. We collected the APACHE II score, length of ICU stay and mortality. Potential ALI risk factors were scored as positive when present 48 hours prior to onset of ALI, including trauma, elective and emergency surgery, lung contusion, aspiration, massive transfusion, pancreatitis, 
pneumonia, sepsis and mechanical ventilation. Life support measures requiring the use of inotropic or vasopressor support were also scored.

Co-interventions that may influence outcome of ALI were scored, including mechanical ventilation with tidal volumes $\leq 8 \mathrm{ml} / \mathrm{kg}$ [32], restrictive fluid strategy (net fluid balance in the first 7 days $<0 \mathrm{ml}$ ) [33], use of APC [11] and use of steroids ( $>300 \mathrm{mg}$ hydrocortisone per day or the equivalent) [34]. Co-morbidities that influence use of heparin were scored, including myocardial infarction, surgery and hematologic malignancy. Laboratory parameters scored on admission included platelet count, prothrombin time (PT) and activated partial thrombin time (aPTT).

\section{Outcome measures}

The primary outcome measure was mortality over 28 days. Secondary outcome variables included 90 day mortality. Mortality data was cross-checked with the Dutch Civil Registry. Safety of heparin administration was assessed by comparing the need for allogeneic blood transfusion.

\section{Statistical analysis}

Continuous variables are expressed as mean and standard deviation or medians and interquartile ranges depending on distribution. Categorical variables are expressed as $\mathrm{n}$ (\%). Comparison between groups was done with Student's $t$-test or Mann-Whitney $U$ test depending on distribution. Categorical variables were compared with the Chi-square test or Fisher's exact test.

Cases were defined as patients who died within 28 days of admission to the ICU. Cases were matched to controls using propensity analysis $[35,36]$. Propensity score was calculated by a multivariable logistic regression model with heparin as the dependent variable, while all other covariates related to mortality were included as independent variables. Covariates included age, sex, APACHE II score, pre-existing medical condition (trauma, sepsis, aspiration, pancreatitis, pneumonia, massive transfusion), recent surgical history, respiratory failure requiring mechanical ventilation, cardiovascular failure requiring inotropic/vasopressor support and cointerventions for ALI (use of APC or steroids, limited tidal volume ventilation, restrictive fluid strategy). The joint probability of these covariates to predict heparin use is used to match cases with controls in a 1 to 3 fashion, to control for confounding and bias due to nonrandom selection of patients. We considered there might be a causal relation between heparin treatment and APACHE II score as both may occur within the 24 hours following admission, therefore we calculated propensity scores both with and without using the APACHE II score in our model.
Heparin use related to 28 days mortality as well as to 90 days mortality was investigated using conditional logistic regression. As effects of heparin may actually reflect effects related to a prolonged aPTT, comparisons were repeated between patients with an aPTT of $45 \mathrm{sec}-$ onds or more and an aPTT of less than 45 seconds, using a mixed ANOVA model for repeated measures (4 measurements). Furthermore, we used a Cox proportional hazards model with 28-day mortality as the dependant variable and heparin use and propensity scores as covariates, in order to estimate the relative impact of heparin use on 28-day all-cause mortality.

Statistical analysis was conducted with SPSS version 16.0 (SPSS Inc., Chicago, IL, USA).

\section{Results}

\section{Patient populations}

During the screening period, 5,561 patients were admitted to our ICU. Of these, 398 patients were re-admissions, 288 died within 48 hours and 2,737 were discharged from the ICU within 48 hours, leaving 2,138 patients for screening of the presence of ALI (Figure 1). Of these, 1,415 patients did not meet ALI criteria, leaving 723 patients for analysis. The inter observer agreement for the diagnosis of ALI was good (weighted kappa 0.61).

Of the 723 patients, 164 patients received therapeutic dose intravenous heparin. Baseline characteristics of the (unmatched) patients are shown in Table 1. Outcome did not differ between unmatched patient groups. Groups were unbalanced with respect to age, APACHE II score and type of admission diagnosis.

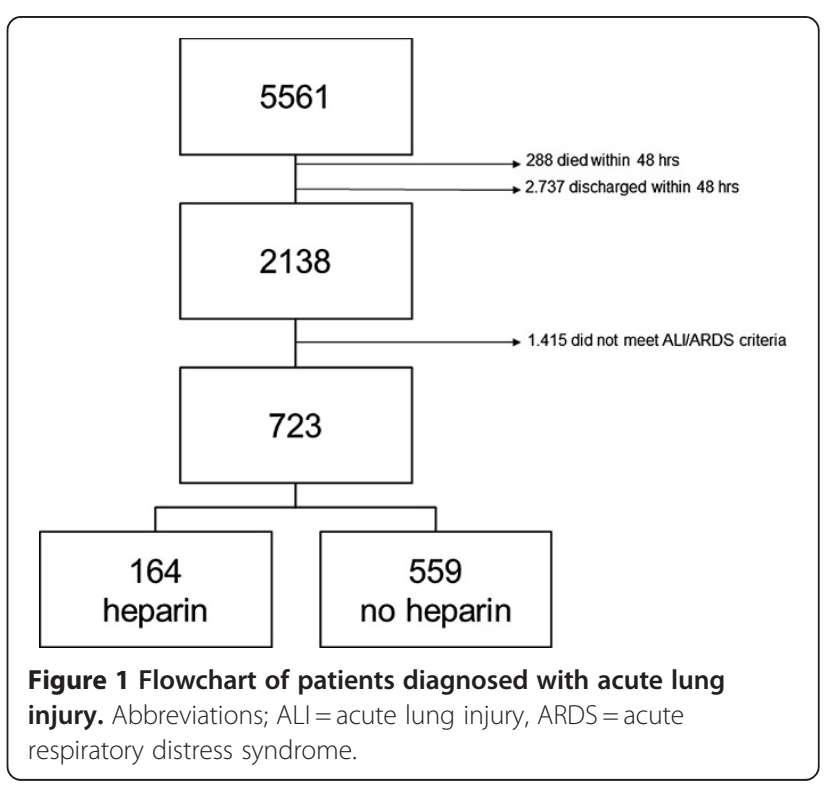


Table 1 Patient characteristics and outcome of unmatched ALI patients

\begin{tabular}{|c|c|c|c|}
\hline & No Heparin $n=559$ & Heparin $n=164$ & $p$ value \\
\hline Age, mean (SD) & $59(17)$ & $63(14)$ & 0.003 \\
\hline Male,\% (n) & 70 (389) & $63(103)$ & 0.10 \\
\hline APACHE II score, mean (SD) & $17.8(6.9)$ & $19.8(6.5)$ & 0.001 \\
\hline Medical patients,\% (n) & $60(334)$ & $71(117)$ & 0.007 \\
\hline Surgery elective,\% (n) & $23(128)$ & $19(31)$ & 0.28 \\
\hline Surgery emergency,\% (n) & $17(97)$ & $7(16)$ & 0.02 \\
\hline \multicolumn{4}{|l|}{ Medical condition } \\
\hline Multiple Trauma,\% (n) & $8(43)$ & $2(3)$ & 0.007 \\
\hline Sepsis,\% (n) & $21(115)$ & $18(29)$ & 0.42 \\
\hline Diabetes,\% (n) & $14(81)$ & $16(27)$ & 0.53 \\
\hline Liver Failure,\% (n) & $3(14)$ & $2(4)$ & 0.96 \\
\hline Hematological malignancy,\% (n) & $6(35)$ & $2(3)$ & 0.03 \\
\hline Aspiration,\% (n) & $5(26)$ & $4(6)$ & 0.59 \\
\hline Pancreatitis,\% (n) & $2(12)$ & $2(4)$ & 0.82 \\
\hline Pneumonia,\% (n) & $23(129)$ & $10(17)$ & $<0.001$ \\
\hline COPD & $11(62)$ & $14(23)$ & 0.31 \\
\hline Auto immune disease,\% (n) & $6(34)$ & $9(15)$ & 0.17 \\
\hline Previous Myocardial infarction,\% (n) & $13(72)$ & $40(66)$ & $<0.001$ \\
\hline Immune Compromised,\% (n) & $11(61)$ & $6(10)$ & 0.07 \\
\hline Massive Transfusion,\% (n) & $14(78)$ & $12(19)$ & 0.43 \\
\hline \multicolumn{4}{|l|}{ Life support measures } \\
\hline Respiratory failure (MV) $\%$ (n) & $93(519)$ & $95(156)$ & 0.42 \\
\hline Cardiovascular failure (MI), \% (n) & $13(72)$ & $40(66)$ & $<0.001$ \\
\hline \multicolumn{4}{|l|}{ Co interventions } \\
\hline Activated Protein C,\% (n) & $4(24)$ & $1(1)$ & 0.02 \\
\hline Stress dose steroids, $\%$ (n) & $42(233)$ & $46(76)$ & 0.29 \\
\hline Protective mechanical ventilation $(<8 \mathrm{ml} / \mathrm{kg}), \%(\mathrm{n})$ & $54(304)$ & $55(91)$ & 0.29 \\
\hline Restrictive fluid strategy (net fluid balance first 7 days $\leq 0 \mathrm{ml}$ ) $\%$ (n) & $36(203)$ & $35(58)$ & 0.82 \\
\hline \multicolumn{4}{|l|}{ Outcome } \\
\hline 28 days mortality, $\%(n)$ & $24(134)$ & $30(50)$ & 0.09 \\
\hline 90 days mortality,\% (n) & $32(181)$ & $39(64)$ & 0.11 \\
\hline ICU-stay, median (IQR) & $7(4-13)$ & $7(4-13)$ & 0.59 \\
\hline Hospital-stay, median (IQR) & $20(11-38)$ & $18(8-37)$ & 0.13 \\
\hline
\end{tabular}

$A P A C H E=$ Acute Physiology and Chronic Health Evaluation, $C O P D=$ chronic obstructive pulmonary disease, $I Q R=$ interquartile range, $M I=$ myocardial infarction, $M V=$ mechanical ventilation, $S D=$ standard deviation.

\section{Propensity matching}

Using logistic regression analysis, risk factors for 28-day mortality were determined, shown in Table 2. As expected, old age and high APACHE II scores were risk factors for mortality in ALI patients, whereas undergoing elective surgery protected against mortality. Diabetes, liver failure, autoimmune disease and a compromised immune state were risk factors for mortality in this cohort. Of interest, cardiovascular failure did not contribute to mortality in ALI patients. Application of limited tidal volume ventilation and the restrictive use of fluids were confirmed as protective measures in this cohort of ALI patient. Interestingly, a stress dose steroid regimen contributed to mortality in this cohort of ALI patients. The covariates that significantly contributed to outcome (including APACHE II score) were used in a propensity-based analysis of the risk to die of patients who had received heparin and controls, which is shown in Table 3 . Suitable propensity matches were found for all patients receiving heparin. Use of heparin did not alter mortality risk compared to controls. 
Table 2 Multivariate logistic regression analysis of covariates for the risk of 28-day mortality in ALI patients

\begin{tabular}{|c|c|c|}
\hline & OR $(95 \% \mathrm{Cl})$ & $P$ value* \\
\hline Age & $1.02(1.00 / 1.03)$ & 0.002 \\
\hline Male & $1.39(0.92 / 1.86)$ & 0.13 \\
\hline APACHE II score & $1.09(1.06 / 1.12)$ & $<0.001$ \\
\hline Medical & $1.94(1.34 / 2.81)$ & $<0.001$ \\
\hline Surgery Elective & $0.40(0.25 / 0.65)$ & $<0.001$ \\
\hline Surgery Emergency & $0.91(0.57 / 1.45)$ & 0.68 \\
\hline \multicolumn{3}{|l|}{ Medical conditions } \\
\hline Multiple Trauma & $0.51(0.22 / 1.15)$ & 0.11 \\
\hline Sepsis & $1.27(0.84 / 1.90)$ & 0.25 \\
\hline Diabetes & $1.83(1.18 / 2.83)$ & 0.006 \\
\hline Liver Failure & $3.82(1.48 / 9.82)$ & 0.006 \\
\hline Hematological malignancy & $1.77(0.89 / 3.49)$ & 0.10 \\
\hline Aspiration & $1.35(0.63 / 2.91)$ & 0.44 \\
\hline Pancreatitis & $0.67(0.19 / 2.38)$ & 0.54 \\
\hline Pneumonia & $1.14(0.75 / 1.71)$ & 0.55 \\
\hline COPD & $1.26(0.76 / 2.07)$ & 0.37 \\
\hline Auto immune disease & $1.95(1.07 / 3.56)$ & 0.03 \\
\hline Previous Myocardial infarction & $1.25(0.83 / 1.89)$ & 0.29 \\
\hline Immune Compromised & $1.69(1.00 / 2.83)$ & 0.05 \\
\hline Massive Transfusion & $0.68(0.40 / 1.16)$ & 0.16 \\
\hline \multicolumn{3}{|l|}{ Life support measures } \\
\hline Respiratory failure at admission & $1.00(0.98 / 1.02)$ & 0.99 \\
\hline Cardiovascular failure (inotropic at admission) & $1.00(0.98 / 1.02)$ & 0.84 \\
\hline \multicolumn{3}{|l|}{ Co interventions } \\
\hline Activated Protein C & $1.40(0.59 / 3.29)$ & 0.45 \\
\hline Stress dose steroids & $1.89(1.34 / 2.64)$ & $<0.001$ \\
\hline Protective mechanical ventilation $(<8 \mathrm{ml} / \mathrm{kg})$ & $0.63(0.45 / 0.89)$ & 0.008 \\
\hline Restrictive fluid strategy (net fluid balance first 7 days $\leq 0 \mathrm{ml}$ ) & $0.33(0.22 / 0.49)$ & $<0.001$ \\
\hline
\end{tabular}

* Potentially confounder ( $p$ value $\leq 0.10$ ). COPD $=$ chronic obstructive pulmonary disease, $O R=$ odds ratio, $C I=95 \%$ confidence limit.

\section{Primary and secondary outcome}

The length of ICU stay was also not different in the heparin group compared to the control group, p 0.59 (Table 1). A repeated analysis leaving out the APACHE II score yielded similar results. Heparin use did not influence mortality, as it affected neither 28-day (1.23 $(0.80 / 1.89) \mathrm{p}=0.34)$ nor 90-day mortality (1.27 (0.85/ 1.89) $\mathrm{p}=0.24)$.

As any possible protective effect of heparin on the occurrence of ALI may be due to dose, reflected by prolongation of the activated partial thromboplastin time
(aPTT), odds ratio's for mortality were recalculated stratified for aPTT (Table 4). In all ALI patients and in those using heparin, a prolonged aPTT did not protect against mortality. In patients not receiving heparin, an $\mathrm{aPTT}<45$ seconds was found to protect against mortality.

In an unadjusted Cox model, the risk of mortality did not differ in patients who had received heparin compared to patients who had not received heparin [hazard ratio (HR) 0.97 ; 95\% CI 0.67-1.40; p 0.87]. Adjustment for propensity score did not alter risk of mortality

Table 3 Conditional logistic regression of mortality of patients with acute lung injury matched using propensity score

\begin{tabular}{lccc}
\hline & Mortality rate (No. deaths/total No. of patients) & OR (95\% CI) & $\boldsymbol{p}$ \\
\hline Heparin use' (28-day mortality) & $30(50 / 164)$ & $1.22(0.79 / 1.90)$ & 0.36 \\
Heparin use' (90-day mortality) & $39(64 / 164)$ & $1.08(0.73 / 1.59)$ & 0.71 \\
\hline
\end{tabular}

${ }^{1}$ Matched with propensity score. 
Table 4 Mortality over 28 days in patients with acute lung injury stratified for aPTT

\begin{tabular}{|c|c|c|c|}
\hline & Mortality rate (No. deaths/total No. of patients) & OR $(95 \% \mathrm{Cl})$ & $p$ \\
\hline aPTT $\leq 45$ (all patients) & $25.4(184 / 723)$ & $0.64(0.43 / .96)$ & 0.03 \\
\hline aPTT $\leq 45^{1}$ (patients using heparin) & $31(50 / 164)$ & $0.66(0.30 / 1.45)$ & 0.26 \\
\hline $\mathrm{aPTT} \leq 45^{2}$ (patients not using heparin) & $24(134 / 559)$ & $0.54(0.34 / 0.87)$ & 0.007 \\
\hline Pooled results ${ }^{1,2}$ & & $0.57(0.38 / 0.86)$ & 0.005 \\
\hline
\end{tabular}

(adjusted HR 0.82; 95\% CI 0.57-1.19; p 0.30). Figure 2 expresses cumulative survival in both groups using this model.

The need for allogeneic blood transfusion during ICU stay did not differ between the heparin-treated group and the control group ( $44 \%$ vs. $47 \%, \mathrm{p}=0.3)$, nor the mean amount of red blood cells units transfused $(0.9 \pm 0.8$ vs. $0.9 \pm 1.0, \mathrm{p}=0.5)$.

\section{Discussion}

In this retrospective, propensity matched case control study, the use of a therapeutic dose of unfractionated heparin was not associated with a decrease in mortality in critically ill patients with ALI. Based on these results, heparin does not seem to benefit patients with ALI.

These results are in contrast with previous experimental reports suggesting that intravenous heparin favorably influences outcome in ALI $[23,37,38]$ and also with a prospective study, in which nebulized heparin significantly reduced coagulation activation in the lungs of critically ill ALI patients [28] and shortened duration of mechanical ventilation [39].

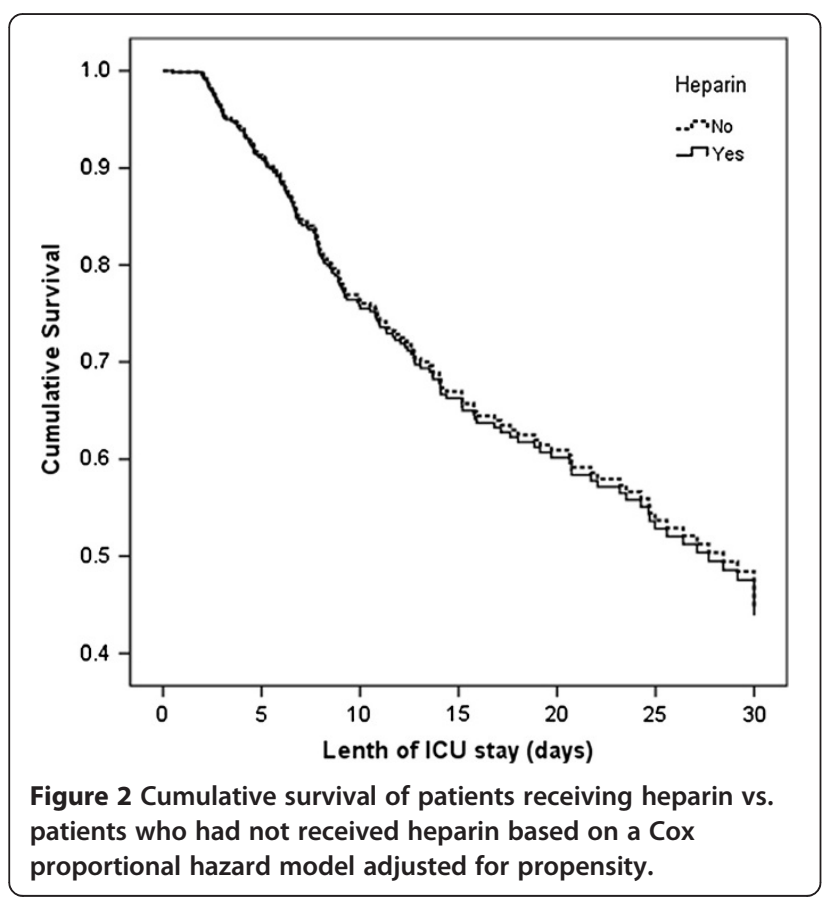

Our study has some important limitations. First and foremost, sample size may have been too small to demonstrate a statistically significant impact on mortality. The study was not designed to look for an effect of heparin on ALI and may have been underpowered. Indeed, interventions studied in randomized trials with a proven effect on outcome in ALI have required a large number of patients [32,33]. We were not able to measure markers of inflammation in the groups and cannot comment on the ability of intravenous heparin to influence inflammation in ALI.

Second, the retrospective nature of the study design is subject to bias. Indeed, groups differed in several baseline characteristics. In an effort to limit confounding, propensity analysis was performed, which resulted in elimination of these baseline differences. Although retrospective analyses cannot replace the advantage of randomization, propensity analyses may be a way of reducing bias when assessing treatment effects [36]. It is possible that some patients were already receiving heparin upon ICU admission. Since APACHE II score is calculated in the first 24 hours of ICU admission, one could question the justification of using APACHE II score when calculating propensity for heparin. However, a repeat analysis without APACHE II score resulted in similar findings. However, this method may still allow for confounders unaccounted for. Another possible baseline difference that could not be accounted for in the propensity analysis is the dose of heparin used, as heparin treatment regimen was not standardized in this retrospective analysis. Indications for the use of heparin were not scored and heparin dose in our ICU differs depending on indication (e.g., suspected thromboembolism or anticoagulant requirement due to use of renal replacement therapy). Therefore, analyses were repeated according to aPTT. Prolonged aPTT also did not yield protection in ALI patients. Another explanation could be the low levels of pulmonary antithrombin (AT). The anticoagulant effects of heparin are exerted via $\mathrm{AT}$, and it may well be that AT consumption leads to impaired actions of heparin. Previous animal studies have demonstrated that AT combined with heparin effectively reduces acute lung injury [40].

Third, as the focus of inflammation in ALI patients is in the lungs and nebulized heparin was protective in ALI $[28,39]$, it may be possible that the use of nebulized 
heparin instead of intravenous heparin would have yielded an effect on outcome in this study, as found before $[38,41]$. We cannot comment on this issue, as the intravenous route is currently standard clinical practice.

Fourth, a potential benefit of the use of heparin on outcome may have been offset by complications of the use of heparin, in particular bleeding. Although we were unable to score bleeding in this retrospective analysis, it seems unlikely that bleeding influenced mortality in this study, given that groups did not differ in their need for allogeneic blood transfusion.

\section{Conclusions}

In conclusion, administration of therapeutic doses of intravenous unfractionated heparin was not associated with reduced mortality in critically ill patients diagnosed with ALI. Heparin treatment did not increase (bleeding) complications.

\section{Future investigations}

In view of the limitations of our study design and the abundant data from previous (pre-) clinical investigations, a prospective clinical trial is warranted to investigate the potential of heparin treatment in critically ill patients diagnosed with ALI. Since coagulopathy in acute lung injury is for the most part restricted to the lung, future investigations may include local treatment allowing increased local efficacy while reducing the risk on systemic bleeding.

\section{Abbreviations \\ rh-APC, Recombinant human activated protein C; ALI, Acute lung injury; ARDS, Acute respiratory distress syndrome; aPTT, Activated partial thrombin time; APACHE II, Acute Physiology And Chronic Health Evaluation II; AT, Antithrombin; Cl, Confidence interval; ICU, Intensive care unit; OR, Odds ratio; PT, Prothrombin time.}

\section{Competing interests}

The author(s) declare that they have no competing interests.

\section{Authors' contributions}

$\mathrm{JJH}$ participated in the design of the study, participated in collecting and analyzing the data, participated in the conduction of statistical analysis and participated in drafting of the manuscript. APV participated in collecting and analyzing the data and participated in drafting of the manuscript. DP participated in collecting and analyzing the data and participated in drafting of the manuscript. GK participated in collecting and analyzing the data and participated in drafting of the manuscript. ML participated in the design of the study and participated in drafting of the manuscript. MJS participated in the design of the study and participated in drafting of the manuscript. JMB coordinated in the conduction of statistical analysis and participated in drafting of the manuscript. NPJ participated in the design of the study, participated in collecting and analyzing the data, participated in the conduction of statistical analysis and participated in drafting of the manuscript. All authors have read and approved the final manuscript.

\section{Author details}

${ }^{1}$ Department of Intensive Care Medicine, Academic Medical Center, University of Amsterdam, Meibergdreef 9, 1105 AZ Amsterdam, The Netherlands. ${ }^{2}$ Laboratory for Experimental Intensive Care and Anesthesiology (L.E.I.C.A.), Academic Medical Center, University of
Amsterdam, Meibergdreef 9, 1105 AZ Amsterdam, The Netherlands. ${ }^{3}$ Department of Anesthesiology, Academic Medical Center, University of Amsterdam, Meibergdreef 9, 1105 AZ Amsterdam, The Netherlands. ${ }^{4}$ Department Internal Medicine of the Academic Medical Center, University of Amsterdam, Meibergdreef 9, 1105 AZ Amsterdam, the Netherlands. ${ }^{5}$ Department of Medicine, University of Cambridge, Cambridge, UK.

Received: 14 December 2011 Accepted: 28 July 2012

Published: 15 August 2012

\section{References}

1. Levi M, Ten $\mathrm{CH}$ : Disseminated intravascular coagulation. N Engl J Med 1999, 341:586-592.

2. Schultz MJ, Haitsma JJ, Zhang H, Slutsky AS: Pulmonary coagulopathy as a new target in therapeutic studies of acute lung injury or pneumonia-a review. Crit Care Med 2006, 34:871-877.

3. Dahlem P, Bos AP, Haitsma JJ, Schultz MJ, Meijers JC, Lachmann B: Alveolar fibrinolytic capacity suppressed by injurious mechanical ventilation. Intensive Care Med 2005, 31:724-732.

4. Dahlem P, Bos AP, Haitsma JJ, Schultz MJ, Wolthuis EK, Meijers JC, Lachmann B: Mechanical ventilation affects alveolar fibrinolysis in LPS-induced lung injury. Eur Respir J 2006, 28:992-998.

5. Choi G, Schultz MJ, Levi M, van der Poll T, Millo JL, Garrard CS: Protein C in pneumonia. Thorax 2005, 60:705-706

6. Ware LB, Fang $X$, Matthay MA: Protein $C$ and thrombomodulin in human acute lung injury. Am J Physiol Lung Cell Mol Physiol 2003, 285:L514-L521.

7. Welty-Wolf KE, Carraway MS, Ortel TL, Piantadosi CA: Coagulation and inflammation in acute lung injury. Thromb Haemost 2002, 88:17-25.

8. Gunther A, Mosavi P, Heinemann S, Ruppert C, Muth H, Markart P, Grimminger F, Walmrath D, Temmesfeld-Wollbruck B, Seeger W: Alveolar fibrin formation caused by enhanced procoagulant and depressed fibrinolytic capacities in severe pneumonia. Comparison with the acute respiratory distress syndrome. Am J Respir Crit Care Med 2000, 161:454-462

9. Ware LB, Matthay MA, Parsons PE, Thompson BT, Januzzi JL, Eisner MD, National Heart LaBIARDSCTN: Pathogenetic and prognostic significance of altered coagulation and fibrinolysis in acute lung injury/acute respiratory distress syndrome. Crit Care Med 2007, 35:1821-1828.

10. Bernard GR, Vincent JL, Laterre PF, LaRosa SP, Dhainaut JF Lopez-Rodriguez A, Steingrub JS, Garber GE, Helterbrand JD, Ely EW, et al: Efficacy and safety of recombinant human activated protein $\mathrm{C}$ for severe sepsis. N Engl J Med 2001, 344:699-709.

11. FDA (online source): Xigris [drotrecogin alfa (activated)]: Market Withdrawal - Failure to Show Survival Benefit. 2012.

12. Laterre PF, Abraham E, Janes JM, Trzaskoma BL, Correll NL, Booth FV: ADDRESS (ADministration of DRotrecogin alfa [activated] in Early stage Severe Sepsis) long-term follow-up: one-year safety and efficacy evaluation. Crit Care Med 2007, 35:1457-1463.

13. Hofstra JJ, Haitsma JJ, Juffermans NP, Levi M, Schultz MJ: The role of bronchoalveolar hemostasis in the pathogenesis of acute lung injury. Semin Thromb Hemost 2008, 34:475-484.

14. Ware LB, Bastarache JA, Wang L: Coagulation and fibrinolysis in human acute lung injury-new therapeutic targets? Keio J Med 2005, 54:142-149.

15. Zarychanski R, Doucette S, Fergusson D, Roberts D, Houston DS, Sharma S, Gulati $H$, Kumar A: Early intravenous unfractionated heparin and mortality in septic shock. Crit Care Med 2008, 36:2973-2979.

16. Jaimes F, De La Rosa G, Morales C, Fortich F, Arango C, Aguirre D, Muñoz A: Unfractioned heparin for treatment of sepsis: a randomized clinical trial (The HETRASE Study). Crit Care Med 2009, 37:1185-1196.

17. Sebag SC, Bastarache JA, Ware LB: Therapeutic Modulation of Coagulation and Fibrinolysis in Acute Lung Injury and the Acute Respiratory Distress Syndrome. Curr Pharm Biotechnol 2011, 12:1481-1496.

18. Ware LB, Camerer E, Welty-Wolf K, Schultz MJ, Matthay MA: Bench to bedside: targeting coagulation and fibrinolysis in acute lung injury. Am J Physiol Lung Cell Mol Physiol 2006, 291:L307-L311.

19. Hofstra JJ, Juffermans NP, Schultz MJ, Zweers MM: Pulmonary coagulopathy as a new target in lung injury-a review of available pre-clinical models. Curr Med Chem 2008, 15:588-595. 
20. Lantz M, Thysell H, Nilsson E, Olsson I: On the binding of Tumor Necrosis Factor (TNF) to heparin and the release in vivo of the TNF-binding protein I by heparin. J Clin Invest 1991, 88:2026-2031.

21. Lever R, Hoult JR, Page CP: The effects of heparin and related molecules upon the adhesion of human polymorphonuclear leucocytes to vascular endothelium in vitro. Br J Pharmacol 2000, 129:533-540.

22. Pernerstorfer $T$, Hollenstein $U$, Hansen J, Knechtelsdorfer M, Stohlawetz $P$, Graninger W, Eichler HG, Speiser W, Jilma B: Heparin blunts endotoxininduced coagulation activation. Circulation 1999, 100:2485-2490.

23. Darien BJ, Fareed J, Centgraf KS, Hart AP, MacWilliams PS, Clayton MK, Wolf H, Kruse-Elliott KT: Low molecular weight heparin prevents the pulmonary hemodynamic and pathomorphologic effects of endotoxin in a porcine acute lung injury model. Shock 1998, 9:274-281.

24. Slofstra SH, van't Veer C, Buurman WA, Reitsma PH, ten Cate H, Spek CA: Low molecular weight heparin attenuates multiple organ failure in a murine model of disseminated intravascular coagulation. Crit Care Med 2005, 33:1365-1370.

25. Cox CS Jr, Zwischenberger JB, Traber DL, Traber LD, Haque AK, Herndon DN: Heparin improves oxygenation and minimizes barotrauma after severe smoke inhalation in an ovine model. Surg Gynecol Obstet 1993, 176:339-349.

26. Mu E, Ding R, An X, Li X, Chen S, Ma X: Heparin attenuates lipopolysaccharide-induced acute lung injury by inhibiting nitric oxide synthase and TGF-beta/Smad signaling pathway. Thromb Res 2012, 129:479-485.

27. Li LF, Yang CT, Huang CC, Liu YY, Kao KC, Lin HC: Low-molecular-weight heparin reduces hyperoxia-augmented ventilator-induced lung injury via serine/threonine kinase-protein kinase B. Respir Res 2011, 12:90.

28. Dixon B, Schultz MJ, Hofstra JJ, Campbell DJ, Santamaria JD: Nebulized heparin reduces levels of pulmonary coagulation activation in acute lung injury. Crit Care 2010, 14:445.

29. Vlaar AP, Binnekade JM, Prins D, van Stein D, Hofstra JJ, Schultz MJ, Juffermans NP: Risk factors and outcome of transfusion-related acute lung injury in the critically ill: a nested case-control study. Crit Care Med 2010, 38:771-778.

30. Bernard GR, Artigas A, Brigham KL, Carlet J, Falke K, Hudson L, Lamy M, LeGall JR, Morris A, Spragg R: The American-European Consensus Conference on ARDS. Definitions, mechanisms, relevant outcomes, and clinical trial coordination. Am J Respir Crit Care Med 1994, 149:818-824.

31. Gajic $O$, Gropper MA, Hubmayr RD: Pulmonary edema after transfusion: how to differentiate transfusion-associated circulatory overload from transfusion-related acute lung injury. Crit Care Med 2006, 34:S109-S113.

32. The Acute Respiratory Distress Syndrome Network: Ventilation with lower tidal volumes as compared with traditional tidal volumes for acute lung injury and the acute respiratory distress syndrome. N Engl J Med 2000, 342:1301-1308.

33. Wiedemann HP, Wheeler AP, Bernard GR, Thompson BT, Hayden D, deBoisblanc B, Connors AF Jr, Hite RD, Harabin AL: Comparison of two fluid-management strategies in acute lung injury. N Engl J Med 2006, 354:2564-2575.

34. Meduri GU, Headley AS, Golden E, Carson SJ, Umberger RA, Kelso T, Tolley EA: Effect of prolonged methylprednisolone therapy in unresolving acute respiratory distress syndrome: a randomized controlled trial. JAMA 1998, 280:159-165.

35. Glynn RJ, Schneeweiss S, Sturmer T: Indications for propensity scores and review of their use in pharmacoepidemiology. Basic Clin Pharmacol Toxicol 2006, 98:253-259.

36. Luellen JK, Shadish WR, Clark MH: Propensity scores: an introduction and experimental test. Eval Rev 2005, 29:530-558.

37. Abubakar K, Schmidt B, Monkman S, Webber C, DeSA D, Roberts R: Heparin improves gas exchange during experimental acute lung injury in newborn piglets. Am J Respir Crit Care Med 1998, 158:1620-1625.

38. Murakami K, McGuire R, Cox RA, Jodoin JM, Bjertnaes LJ, Katahira J, Traber LD, Schmalstieg FC, Hawkins HK, Herndon DN, et al: Heparin nebulization attenuates acute lung injury in sepsis following smoke inhalation in sheep. Shock 2002, 18:236-241.

39. Dixon B, Schultz MJ, Smith R, Fink JB, Santamaria JD, Campbell DJ: Nebulized heparin is associated with fewer days of mechanical ventilation in critically ill patients: a randomized controlled trial. Crit Care 2010, 14:R180
40. Iba T, Kidokoro A, Fukunaga M, Nagakari K, Suda M, Yoshikawa S, Ida Y: Antithrombin ameliorates endotoxin-induced organ dysfunction more efficiently when combined with danaparoid sodium than with unfractionated heparin. Intensive Care Med 2005, 31:1101-1108.

41. Murakami K, Enkhbaatar P, Shimoda K, Mizutani A, Cox RA, Schmalstieg FC, Jodoin JM, Hawkins HK, Traber LD, Traber DL: High-dose heparin fails to improve acute lung injury following smoke inhalation in sheep. Clin Sci (Lond) 2003, 104:349-356.

doi:10.1186/1471-2466-12-43

Cite this article as: Hofstra et al: Early intravenous unfractionated heparin and outcome in acute lung injury and acute respiratory distress syndrome - a retrospective propensity matched cohort study. BMC Pulmonary Medicine 2012 12:43.

\section{Submit your next manuscript to BioMed Central and take full advantage of:}

- Convenient online submission

- Thorough peer review

- No space constraints or color figure charges

- Immediate publication on acceptance

- Inclusion in PubMed, CAS, Scopus and Google Scholar

- Research which is freely available for redistribution 